\title{
Missing intrauterine devices, laparoscopic and a conventional management: A single-center experience
}

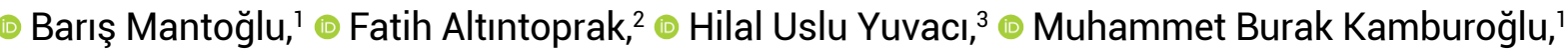 \\ ๑ Mehmet Aziret, ${ }^{4} \odot$ Emre Gönüllü, ${ }^{\oplus}$ Emrah Akın ${ }^{1}$ \\ 'Department of General Surgery, Sakarya University Training and Research Hospital, Sakarya, Turkey \\ ${ }^{2}$ Department of General Surgery, Sakarya University Faculty of Medicine, Sakarya, Turkey \\ ${ }^{3}$ Department of Obstetrics and Gynecology, Sakarya University Faculty of Medicine, Sakarya, Turkey \\ ${ }^{4}$ Department of Gastroenterological Surgery, Sakarya University Training and Research Hospital, Sakarya, Turkey
}

\begin{abstract}
Introduction: Intrauterine contraception devices (IUCD) are frequently and safely used in pregnancy control. Migration related complications, such as adhesions and perforations, can be encountered as the most important but rare circumstances. In such cases, the laparoscopic approach is beneficial with the least harm principle.

Materials and Methods: This study included ten patients who were admitted to our hospital between 20152019 with chronic abdominal pain, induced by migrated intrauterine devices. Patients' complaints, radiological methods used in diagnosis, IUCD insertion timing, migration of IUCD and time interval to diagnosis, intra-abdominal migration points, and types, as well as surgical interventions, were evaluated retrospectively.

Results: While all patients were diagnosed with abdominal ultrasonography and gynecological examination, some patients underwent computed tomography $60 \%$ and plain radiogram $20 \%$ as additional imaging. While the intra-abdominal migration site of IUCD was ascertained as the most common localization in the lower right quadrant of the omentum (30\%), the placement in the umbilical hernia site was the rarest and the only one in the literature. Three different types of IUCD were detected; Copper-T (80\%) was the most common, while IUCDs were laparoscopically removed in all patients except for the patient who underwent open surgery due to acute cholecystitis. All patients who had laparoscopic surgery were discharged the next day.

Conclusion: In conclusion, the IUCD's frequency of use is increasing as the current method of contraception, dislocation of the device may be encountered if the required conditions are not taken into consideration during the application. In such a situation, laparoscopic removal of a dislocated IUCD is a safe, feasible, and less invasive method.

Keywords: Complication; intrauterine devices; laparoscopy.
\end{abstract}

\section{Introduction}

Intrauterine contraceptive devices (IUCD) are the most common, safe, effective, and convenient way of long-term reversible birth control. Using IUCD has a severe complication such as uterine perforation, which may cause in- frequently with acute symptoms of bowel obstruction or perforation. ${ }^{[1,2]}$ The incidence of uterine perforation is 0.12 to 0.68 per 1000 insertions. ${ }^{[3]}$ The accepted method of extraction of IUCD is surgical extraction, and the surgeon may choose the way even open or laparoscopic due to in- 
traabdominal position of the device. Herein, we described IUCDs which migrated through the abdominal cavity and have the symptoms of the chronic abdominal pain and managed laparoscopically.

\section{Materials and Methods}

This retrospective study included patients who were diagnosed with chronic abdominal pain and lost IUCD during gynecological examination in the general surgery and gynecology and obstetrics outpatient clinic of Sakarya University Training and Research Hospital between 20152019. In addition, a patient undergoing emergency surgery due to perforated acute cholecystitis was included in the study. Patients' age, symptoms, duration of symptoms, imaging methods applied, IUCD type, IUCD placement in the abdomen, surgical intervention, the time interval from the last birth to the IUCD insertion, and the time interval from IUCD insertion to diagnosis were evaluated. A laparoscopic approach was applied in all patients except one patient who has undergone conventional cholecystectomy due to acute cholecystitis. The laparoscopic technique was implemented as described below. After a $10 \mathrm{~mm}$ infra-umbilical incision the $10 \mathrm{~mm}$ trocar introduced through the abdomen with the Hanson technique and insufflated at $12 \mathrm{~mm} / \mathrm{Hg}$. In five patients, the $10 \mathrm{~mm}$ camera port was placed below the umbilicus, while a patient with IUCD migration to the umbilical region inserted $10 \mathrm{~cm}$ lateral from the umbilicus. With the guidance of the Ultracision Harmonic Scalpel (Ethicon, Cincinnati, OH), the attachments of the IUCD to the surrounding tissues separated moreover the IUCD removed with the assistance of an endo bag outside from the abdominal cavity.

\section{Statistical Analysis}

Data were analyzed by descriptive statistics, and percentages and numbers were used for categorical data. The numeric variables were presented as mean \pm standard deviation. Analyses were performed using SPSS statistical software (IBM SPSS Statistics, Version 22.0. Armonk, NY: IBM Corp.)

\section{Results}

The mean age of the patients was $36.7 \pm 1.7$. All patients underwent abdominal ultrasonography (USG) (100\%). Computerized tomography (CT) was performed in 6 patients $(60 \%)$ and plain radiogram in 2 patients (20\%). It was observed that IUCD migrated to various places in the abdomen (Table 1). Among them is the umbilical hernia region as the
Table 1. Descriptive statistics of categorical and numerical variables

\begin{tabular}{|c|c|c|c|c|}
\hline Variables & $\mathbf{n}$ & $\%$ & Mean & SD \\
\hline Age (y) & 10 & & 36.7 & 1.7 \\
\hline \multicolumn{5}{|l|}{ Duration of complaint (m) } \\
\hline Chronic abdominal pain & 10 & & 7 & 4 \\
\hline \multicolumn{5}{|l|}{ Radiological evaluation } \\
\hline USG & 10 & 100 & & \\
\hline CT & 6 & 60 & & \\
\hline Plain Radiogram & 2 & 20 & & \\
\hline \multicolumn{5}{|l|}{ IUCD localization } \\
\hline $\begin{array}{l}\text { Lower right quadrant } \\
\text { inside the omentum }\end{array}$ & 3 & 30 & & \\
\hline Umbilical hernia site & 1 & 10 & & \\
\hline Over bladder & 1 & 10 & & \\
\hline $\begin{array}{l}\text { Left ovary side inside } \\
\text { omentum }\end{array}$ & 1 & 10 & & \\
\hline Douglas space & 1 & 10 & & \\
\hline $\begin{array}{l}\text { Lower left quadrant } \\
\text { inside the omentum }\end{array}$ & 2 & 20 & & \\
\hline $\begin{array}{l}\text { Upper left quadrant } \\
\text { inside the omentum }\end{array}$ & 1 & 10 & & \\
\hline \multicolumn{5}{|l|}{ IUCD insertion time after birth } \\
\hline 1 month & 4 & 40 & & \\
\hline 3 months & 2 & 20 & & \\
\hline 4 months & 2 & 20 & & \\
\hline 5 months & 1 & 10 & & \\
\hline 1 year & 1 & 10 & & \\
\hline $\begin{array}{l}\text { Time interval from IUCD } \\
\text { insertion until diagnosis } \\
\text { of migration }(y)\end{array}$ & 10 & & 4.33 & 3 \\
\hline \multicolumn{5}{|l|}{ Type of IUCD } \\
\hline Copper T & 8 & 80 & & \\
\hline Lippes Loop & 1 & 10 & & \\
\hline Multiload & 1 & 10 & & \\
\hline
\end{tabular}

SD: Standard deviation; USG: Abdominal ultrasonography; CT: Computerized tomography.

point never seen in the literature. The longest and shortest time intervals of IUCD placement were detected as 12 and one-month, respectively. The average time from IUCD insertion to the diagnosis of migration was $4.33 \pm 3$ years. We identified 3 different types of IUCDs in our cases. Copper $\mathrm{T}$ was detected at $80 \%$, while the Lippes loop was found at $10 \%$ and Multiload type at $10 \%$ respectively (Figs. $1-3$ ). Only one of the patients was asymptomatic, at whom IUCD was detected incidentally while undergoing open emer- 

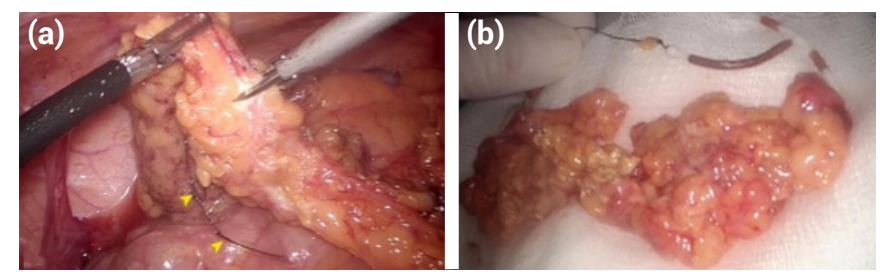

Figure 1. (a) Intraoperative view, guide loops of device (arrows) (b) Extracted device.
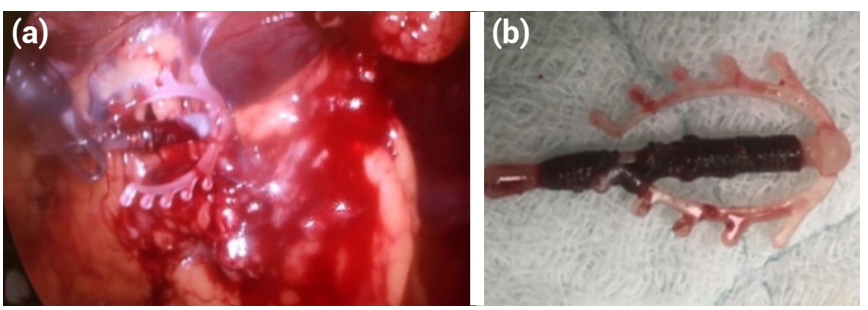

Figure 2. (a) Intraoperative view, guide loops of device (b) Extracted device.

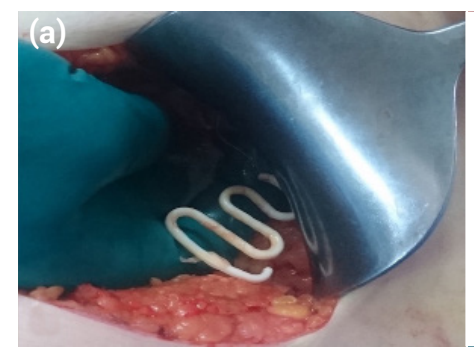

Figure 3. (a) Intraoperative view loops of device (arrows).

gency surgery due to acute cholecystitis. All patients underwent laparoscopic surgery. Postoperative recovery was uneventful, and the patients discharged the next day.

\section{Discussion}

Displacement of IUCD may be most commonly due to expulsion. ${ }^{[4]}$ Many factors are responsible for uterine perforation by IUCDs. The most important causes are the anatomic abnormality of the uterus such as retroversion, the rigidity of IUCD, the timing of insertion, especially lactating mothers having a thin uterine wall, and clinician's in expertise. ${ }^{[5-7]}$ Uterine perforation with IUCD is 10 times more frequent in breastfeeding mothers than in nonbreastfeeding mother. ${ }^{[5,7,8]}$ Considering the patients in our study, all patients had their IUCDs inserted during the lactation period (Table 1). As denoted in one study, Turkey is the country where most of the perforations observed with the IUCD, with a rate of $29.5 \% .{ }^{[9]}$ When it is evaluated from this point, waiting for the time to carry out the process will decrease the perforation rates.

After a careful pelvic examination, the procedure must be performed by an experienced operator or well trained and certified health workers to prevent the displacement of the device. The clinical presentation following perforation and migration is highly variable, ranging from asymptomatic to acute abdomen. Although most of the patients were asymptomatic about their missing devices, pregnancy, chronic abdominal pain, irregular vaginal bleeding, and chronic pelvic inflammatory disease may be a reason to determine the missing IUCD. ${ }^{[9]}$ Except for one, all of our patients admitted to our clinic had chronic abdominal pain furthermore abdominal migration of IUCD detected by examination as well as imaging methods.

After a cautious gynecological examination, the best way to diagnose the missing IUCD is by sonographic scan, which could determine the presence or absence of the IUCD. ${ }^{[10]}$ If not diagnosed with the ultrasound, then plain abdominopelvic $\mathrm{x}$-ray can be performed. CT scan also confirms the position and relationship of the IUCD with abdominopelvic organs there by the surgeon can undoubtedly decide to perform open or laparoscopic surgery. As a result of the radiological evaluation, it is determined that IUCDs migrate to numerous sites in the abdomen. In our study, IUCDs were found to have migrated to seven different spots in the abdomen, and the most striking of these was Multiload IUCD, which has migrated to the umbilical hernia site. Apart from anatomical abnormalities of the uterus and lactation period, the IUCD applied may also be the cause of perforation. When we examined our data, it was noticed that the common migrated IUCD type was Copper-T (80\%). Due to device induced visceral perforation and inflammatory responses, which may cause intestinal obstruction, the World Health Organization, and most authors recommend the removal of IUCD by laparoscopy. ${ }^{[1,12]}$

In a review, Frances R. Mosley et al. ${ }^{[9]}$ support the use of laparoscopic surgery for the elective removal of migrated IUCD from within the peritoneal cavity. We performed nine elective laparoscopic interventions for our patients successfully and they were discharged the next day without any complaint. Sepsis, intestinal perforation needing repair, are contraindications for laparoscopy, there for laparotomy should be the preferred in such cases. ${ }^{[9,13]}$ Conservative management of dislocated asymptomatic IUCD additionally suggested by Aydoğdu et al. in which the patient did not want any removal. ${ }^{[10,14]}$

The limitation of our study is the low number of cases and the data belonging to a single center. However, another 
IUCD migration location that has not yet been described in the literature has been described among our patients.

As a result, IUCD implementation is not an innocent intervention, migration rates will decrease after the necessary actions are taken. If migration of the device occurs, laparoscopic intervention should be preferred in appropriate cases as the first option due to its non-invasiveness and low hospitalization duration.

\section{Disclosures}

Ethichs Committee Approval: Ethics committee approval of our study was obtained from our university. Ethics committee approval no: 04/04/2020 E3925 71522473/050.01.04/113.

Peer-review: Externally peer-reviewed.

Conflict of Interest: The authors declare that they have no conflict of interest.

Authorship Contributions: Concept - B.M., F.A.; Design - B.M., F.A., H.U.Y.; Supervision - M.A.; Materials - E.A., E.G.; Data collection and/or processing - M.B.K., H.U.Y., M.A., E.G.; Analysis and/or interpretation - H.U.Y., M.A., E.G.; Literature search - M.B.K., E.A.; Writing - B.M., F.A.; Critical review - F.A., B.M.

\section{References}

1. Brar R, Doddi S, Ramasamy A, Sinha P. A forgotten migrated intrauterine contraceptive device is not always innocent: A case report. Case Rep Med 2010;2010:740642. [CrossRef]

2. Bitterman A, Lefel O, Segev $Y$, Lavie O. Laparoscopic removal of an intrauterine device following colon perforation. J Soc
Laparoendosc Surg 2010; 14:456-8. [CrossRef]

3. Broso PR, Buffetti G. The IUD and uterine perforation. Minerva Ginecol 1994;46:505-9.

4. Speroff L, Fritz MA, Glass RH. KNC gynaecology endocrinology \& infertility. 7th ed. W\& W; 2005. p. 983.

5. Caliskan E, Öztürk N, Dilbaz BÖ, Dilbaz S. Analysis of risk factors associated with uterine perforation by intrauterine devices. Eur J Contracept Reprod Heal Care 2003;8:150-5.

6. Andersson $\mathrm{K}$, Ryde-Blomqvist $\mathrm{E}$, Lindell $\mathrm{K}$, Odlind $\mathrm{V}$, Milsom I. Perforations with intrauterine devices: Report from a Swedish survey. Contraception 1998;57:251-5. [CrossRef]

7. Heartwell SF, Schlesselman S. Risk of uterine perforation among users of intrauterine devices. Obstet Gynecol 1983;61:31-6.

8. Chi I cheng. What we have learned from recent IUD studies: A researcher's perspective. Contraception 1993;48:81-108.

9. Mosley FR, Shahi N, Kurer MA. Elective surgical removal of migrated intrauterine contraceptive devices from within the peritoneal cavity: A comparison between open and laparoscopic removal. J Soc Laparoendosc Surg 2012;16:236-41.

10. Markovitch O, Klein Z, Gidoni Y, Holzinger M, Beyth Y. Extrauterine mislocated IUD: Is surgical removal mandatory? Contraception 2002;66105-8. [CrossRef]

11. Mechanism of action, safety and efficacy of intrauterine devices. Report of a WHO Scientific Group. World Health Organ Tech Rep Ser 1987;753:1-91.

12. Silva PD, Larson KM. Laparoscopic removal of a perforated intrauterine device from the perirectal fat. JSLS 2000; 4:15962.

13. Mülayim B, Mülayim S, Celik NY. A lost intrauterine device. Guess where we found it and how it happened? Eur J Contracept Reprod Heal Care 2006;11:47-9. [CrossRef]

14. Aydogdu O, Pulat H. Asymptomatic far-migration of an intrauterine device into the abdominal cavity: A rare entity. $J$ Can Urol Assoc 2012;6E134-6. [CrossRef] 